\title{
ITSM: UM CASO DE SUCESSO DO MODELO TRÍPLICE HÉLICE
}

\author{
ITSM: A SUCESS CASE OF \\ THE TRIPLE HELIX MODEL
}

Recebido 17-11-2013 Aceito 20-04-2014

Lia Rosa ${ }^{1}$

\section{RESUMO}

Este artigo objetiva mostrar a consolidação da Incubadora Tecnológica de Santa Maria (ITSM) como um caso de sucesso do Modelo Tríplice Hélice por meio dos elos estabelecidos pela Incubadora ao longo da trajetória do projeto, o qual teve início em 1999. Com base nas ações desenvolvidas e estimuladas desde a concepção do projeto até sua fase atual, procura-se elucidar as contribuições da ITSM para o desenvolvimento sustentável da região central do Estado do Rio Grande do Sul. A metodologia utilizada foi o estudo de caso, em que se desenvolveu um estudo exploratório e descritivo. Dentre os fatores que destacam a atuação da ITSM, foi possível evidenciar seu papel como organização híbrida dentro do Sistema Tríplice Hélice - tanto por possuir as características dos três atores do Sistema como pela permanente tentativa de unir os atores envolvidos.

Palavras-chave: Incubadora de Empresas, Modelo Tríplice Hélice, Desenvolvimento Regional, ITSM

${ }^{1}$ Possui graduação em Educação Física pela Universidade Federal de Santa Maria - UFSM e graduação em Direito pelo Centro Universitário Franciscano - UNIFRA. Atualmente é membro do corpo editorial da InterAção. Santa Maria, Rio Grande do Sul, Brasil. E-mail: lia.fernanda.rosa@gmail.com 


\section{ABSTRACT}

This article aims to show the consolidation of Incubadora Tecnológica de Santa Maria - ITSM - as a success of the Triple Helix Model through the links established by the Incubator along the trajectory of the project, which began in 1999. Through the actions developed and encouraged in this period of time, from conception of the project to its current stage, we try to elucidate the contributions by the ITSM for sustainable development of the central region of Rio Grande do Sul. The methodology used was the study case, where we developed an exploratory descriptive study. Among the factors that highlight the performance of ITSM, it was possible to highlight its role as an organization within the hybrid system Triple Helix - both possess the characteristics of the three actors in the system, as well as the ongoing attempt to unite stakeholders.

Keywords: Business Incubators, Triple Helix Model, Regional Development, ITSM.

\section{INTRODUÇÃO}

A capacidade de gerar conhecimento e transformá-lo em riqueza e desenvolvimento social depende da ação de agentes institucionais responsáveis por gerar e aplicar o conhecimento, que são: governo, universidades e empresas (PALLETTA, 2008). Nesse sentido, as incubadoras de empresas são parte de um sistema nacional de inovação e tecnologia que envolve a interação entre estes autores: instituições de pesquisa e de ensino superior, instituições de fomento, empresas privadas interessadas e organismos governamentais voltados para a transferência de tecnologia, geração e proteção de conhecimento (VEDOVELLO, PUGA, FELIX, 2001).

Em relação ao movimento de incubadoras e parques tecnológicos no Brasil como um todo, nos últimos cinco anos, este movimento, promovido pela Associação Nacional de Entidades Promotoras de Empreendimentos Inovadores (ANPROTEC), cresceu fortemente. O movimento em questão foi causado pela importância cada vez maior dessas instituições como incentivadoras e impulsionadoras do empreendedorismo, da tecnologia e da inovação e como geradoras de desenvolvimento sustentável nas regiões onde estão inseridas.

Assim, dada à importância das incubadoras, torna-se essencial desenvolver programas e projetos que promovam o empreendedorismo inovador dentro de uma universidade, no intuito de conceber e fortalecer novas estratégias que realimentem o processo de desenvolvimento econômico. Dessa maneira, é importante salientar o papel fundamental da interação entre ensino e pesquisa para o desenvolvimento dessas inovações tecnológicas, bem como da interação com o setor privado, a fim de desenvolver ideias adequadas à realidade mercadológica, e com o setor governamental, que pode atuar como aporte financiador das transformações tecnológicas.

Essa abordagem, que coloca a universidade como indutora das relações com as empresas e o governo, visando à produção de novos conhecimentos, à inovação tecnológica e ao desenvolvimento econômico, foi criada por Henry Etzkowitz e Loet Leydesdorff nos anos 1990, mesma época em que o projeto de criação da primeira Incubadora de Empresas de Base Tecnológica (IEBT) do interior do Estado do Rio Grande do Sul estava sendo desenvolvido com objetivo de, por meio da conexão entre os setores público, privado e acadêmico, contribuir para o desenvolvimento da região central do Estado.

Nesse contexto, conforme destacam Arantes e Serpa (2012), as incubadoras de base tecnológica assumem papel de destaque, atuando como agentes de desenvolvimento econômico regional, uma vez que abrigam empresas cujos produtos, processos ou serviços são gerados a partir de resultados de pesquisas aplicadas, nos quais a tecnologia e a inovação representam alto valor agregado. Assim sendo, o objetivo deste trabalho é demonstrar de que maneira a Incuba- 
dora Tecnológica de Santa Maria (ITSM) despontou como um elo entre os atores componentes do Sistema Tripla Hélice, conectando-os ao longo dos anos de atuação do projeto.

\section{FUNDAMENTAÇÃO TEÓRICA}

De acordo com Dias e Carvalho (2002), os programas de incubação de empresas nasceram nos Estados Unidos na década de 1950, da expansão de três diferentes movimentos, que se desenvolveram simultaneamente - o de condomínios de empresas, o de programas de empreendedorismo e o de investimentos em novas empresas de tecnologia. As maiores universidades do país iniciaram programas de empreendedorismo e de geração de inovação em centros de pesquisa, envolvendo alunos e professores no processo de transferência, para a sociedade, dos conhecimentos e das tecnologias produzidos na esfera acadêmica (DIAS; CARVALHO, 2002). Assim sendo, aliado aos condomínios de empresas e aos programas de empreendedorismo, investidores passaram a demonstrar interesse (o que hoje se verifica cada vez mais) em investir em novos empreendimentos surgidos nesses ambientes de inovação.

Já no Brasil, o movimento de incubadoras de empresas é recente e cresceu, sobretudo, na década de 1990. De acordo com informações da Associação Nacional de Entidades Promotoras de Empreendimentos Inovadores (Anprotec), elas começaram a ser criadas a partir de uma iniciativa do Conselho Nacional de Desenvolvimento Científico e Tecnológico (CNPq), na década de 1980, com a implantação do primeiro Programa de Parques Tecnológicos no país.

Segundo o infoDev Incubator Support Center (iDISC, 2012), fonte de informações sobre cultura empreendedora e incubação de empresas, e a Anprotec (2012), existem diversos tipos de incubadoras, dependendo dos tipos de empresas e de suas necessidades e ambições: incubadora tradicional, incubadora de base tecnológica, incubadora mista, incubadora social, incubadora de agronegócios, incubadora de serviços, incubadora setorial e incubadora virtual. Apesar dos diferentes tipos de incubadoras de empresas existentes, seus processos e serviços são geralmente similares, pois seus objetivos são comuns, havendo diferenciação no que tange ao agente fim dos seus serviços.

Segundo Baêta (1999), as incubadoras de empresas de base tecnológica são organizações que abrigam empreendimentos nascentes, geralmente oriundos de pesquisa científica, cujo projeto implica inovações. Tais organizações, conforme o autor, oferecem espaço e serviços subsidiados que favorecem o nascimento de negócios e o desenvolvimento de produtos ou processos de alto conteúdo científico tecnológico e inovador nas áreas de informática, biotecnologia, química fina, novos materiais, mecânica de precisão, entre outros.

De acordo com Labiak (2012, p. 19), "as incubadoras se tornaram presentes em toda parte do mundo, onde os formuladores de políticas de desenvolvimento em nível nacional ou regional, começaram a perceber que este tipo de habitat é uma ferramenta de relevante importância no desenvolvimento econômico, social e inovador das regiões". Essa importância dada às incubadoras no que se refere à sua contribuição para o desenvolvimento é devido ao hábitat de inovação estimulado pelas mesmas, onde o fluxo de conhecimento ocorre com maior naturalidade e o empreendedorismo é altamente estimulado para que as ideias para o desenvolvimento de novos produtos e serviços sejam colocadas em prática e, assim, novos negócios começam a nascer.

O desenvolvimento de produtos de alta tecnologia é visto como mola propulsora do desenvolvimento econômico. Nesse contexto, diversos autores, como Tidd, Bessant e Pavit (2008) e Ferraz (1995), descrevem o processo de inovação como um dos indicadores mais utilizados para avaliar a competitividade, uma vez que seus resultados se encontram vinculados à capacidade de acompanhar as mudanças e o desenvolvimento do mercado, bem como a criação e a ocupação de novos mercados. 
Por sua vez, Porter (2002) acredita que o desenvolvimento da economia nacional passa por políticas que visem ao aumento da competitividade e da produtividade, sendo urgente fazer dessa competitividade uma prioridade nacional, de resolução tanto do setor privado como do Estado. $\mathrm{O}$ autor ressalta, ainda, que "é necessário desenvolver a capacidade de inovação, adaptando as novas tecnologias a todas as áreas produtivas, bem como desenvolver o mercado interno, aumentar os incentivos ao investimento e apostar no desenvolvimento de clusters" (PORTER, 2002).

Assim, a existência de um ambiente propício para o desenvolvimento da inovação tecnológica é fundamental para o crescimento de determinada região. As incubadoras de empresas entram nesse contexto proporcionando condições favoráveis para que as micro e pequenas empresas desenvolvam seus produtos/serviços inovadores e conquistem o mercado.

De acordo com o relatório divulgado pela Anprotec em parceria com o Ministério de Ciência, Tecnologia e Inovação (MCTI) em 2012, atualmente, o Brasil tem 384 incubadoras em operação, que abrigam 2.640 empresas, gerando 16.394 postos de trabalho. Essas incubadoras já graduaram 2.509 empreendimentos, que hoje faturam cerca de $\mathrm{R} \$ \$$ 4,1 bilhões e empregam 29.205 pessoas. O mesmo estudo revelou outro dado importante: $98 \%$ das empresas incubadas inovam, das quais $28 \%$ têm foco no âmbito local, $55 \%$ no nacional e $15 \%$ no mundial. Desse modo, as incubadoras, além de desenvolverem conhecimento tecnológico, geram emprego e renda, contribuindo, naturalmente, para o desenvolvimento da região onde estão instaladas.

Além disso, as incubadoras podem ser vistas como um mecanismo capaz de congregar diversos agentes de inovação - governo, universidade, empresa e sociedade civil organizada - e como parceira para o desenvolvimento tecnológico e social, incentivando a interação entre eles (ETZKOWITZ; LEYDESDORFF 2000). As incubadoras atuam, dessa forma, como um ator articulador desses agentes no chamado Sistema Tríplice Hélice.

A ideia de Hélice Tríplice surgiu em meados dos anos 1990, desenvolvida por Henry Etzkovitz para descrever o modelo de inovação com base na relação governo-universidade-indústria. Segundo o autor, com base em suas observações acerca das relações universidade-empresa-governo, concluiu que somente por meio da interação desses três atores é possível criar um sistema de inovação sustentável e durável na era da economia do conhecimento.

Para Etzkowitz (2005), a interação universidade-empresa-governo é, cada vez mais, a base estratégica para o desenvolvimento social e econômico nas sociedades industriais desenvolvidas e também naquelas em desenvolvimento. De acordo com Etzkowitz e Leydesdorff (2000), a tese da Tríplice Hélice afirma que a universidade pode desempenhar um papel mais importante na inovação em sociedades cada vez mais baseadas no conhecimento. Isso ocorre porque o conhecimento dificilmente será eficientemente transferido para a indústria sem uma série de mecanismos para identificar e melhorar a aplicabilidade dos resultados da pesquisa na prática. Assim, para Etzkowitz e Leydesdorff (2000), os processos de desenvolvimento devem ser realizados por meio de subsídios especiais ou, ainda, em novas empresas formadas em campi e em instalações de incubadoras universitárias.

Para Arantes e Serpa (2012), o processo de inovação vem exigindo, cada vez mais, uma interação entre academia e empresa, sem prescindir da presença do governo como principal agente financiador das transformações tecnológicas. Diante disso, o que se forma é uma tríplice aliança, com esses três atores interagindo de forma a impulsionar o desenvolvimento local e regional sob o amparo da economia do conhecimento. Nesse sentido, "iniciativas relacionadas à criação dos habitats de Inovação, como as Incubadoras de Empresas de Base tecnológicas, têm sido desenvolvidas com maior ênfase nos últimos anos" (ARANTES; SERPA, 2012).

Porter (2002), por seu turno, diz que o sistema tecnológico é insuficiente e que não 
existe uma ligação efetiva entre as universidades e o setor privado, o que é essencial para proporcionar a inovação. Consoante, Chaves (2009) salienta que o papel das universidades nos sistemas nacionais de inovação tem mudado e assumido um lugar estratégico. O novo rumo destes sistemas de inovação, como motor do desenvolvimento econômico local, coloca novas exigências à universidade e levanta questões acerca do papel da investigação universitária nas economias.

De acordo com os formuladores do modelo tripla hélice, tanto a presença das universidades quanto de instituições de ciência e tecnologia com responsabilidade social quanto ao retorno de suas pesquisas, com perfil empreendedor, é fundamental (ETZKOWITZ; LEYDESDORFF, 2000).

Autores como Silva, Terra e Votre (2006) e Zampieri, Casado e Flores (2011) dizem que é preciso acabar com a visão simplista de que as universidades estão limitadas a formar pessoas para a capacitação profissional e para preencher os lugares vazios no mercado de trabalho. Ao contrário, a academia tem ampliado o seu papel na produção de conhecimento, no estabelecimento de novas relações com as empresas e com os governos e na criação de novas áreas de atuação.

A importância da interação desse modelo de relação interinstitucional (universidade -empresa-governo) entre organizações reside em sua natureza distinta, que pode ter finalidades e formas de ação bastante diversas. Nesse modelo, segundo Silva, Terra e Votre (2006), incluemse desde as interações tênues e pouco comprometedoras, como oferecer práticas profissionais, até vínculos institucionais mais intensos, como é o caso de grandes programas de pesquisa cooperativa, em que se chega a repartir os créditos resultantes da comercialização de seus resultados (SILVA, TERRA, VOTRE, 2006).

Segundo Chaves (2009), destacam-se, dentre as funções primordiais da universidade, o ensino, a pesquisa e o empreendedorismo acadêmico. Este último representa a ligação à sociedade por meio do conhecimento produzido e assenta-se em uma mudança de cultura, na qual esta entidade secular, a universidade, canaliza as contribuições da investigação como contributo para a inovação e o crescimento da economia (CHAVES, 2009).

Segundo Arantes e Serpa (2012), é possível ainda que as universidades, sem perderem sua missão central, desenvolvam o papel da indústria no que se refere à formação de empresas (principalmente, por meio das incubadoras) e na transferência de tecnologia. Assim, é possível notar um aumento considerável na cooperação entre a universidade e a indústria, revelado por um crescente reconhecimento da importância da pesquisa universitária para as atividades inovadoras do setor empresarial, principalmente devido aos seguintes fatores, enumerados por Bercovitz e Feldman (2006) apud Chaves (2009): o desenvolvimento de novas plataformas tecnológicas; o crescente conteúdo científico e técnico em todos os tipos de produção industrial; a necessidade de novas fontes de financiamento para as pesquisas acadêmicas; e a proeminência de políticas governamentais visando aumentar os retornos econômicos das pesquisas financiadas por recursos públicos mediante o estímulo à transferência de tecnologia.

Dessa maneira, torna-se imprescindível não só a canalização das contribuições da pesquisa acadêmica para a inovação e o fomento da economia, como também o desenvolvimento de inovações orientadas para as necessidades mercadológicas a fim de que mais facilmente se insiram novos produtos e serviços no mercado por meio das empresas, as quais detêm o interesse de agregar tecnologia em seus produtos e processos.

Apesar de esse modelo parecer ter surgido de uma incapacidade do Estado, de forma isolada, de gerar desenvolvimento sustentável, rápido, efetivo e de qualidade, o que demandou a entrada de outros atores (universidades e empresas) no processo de desenvolvimento socioeconômico, o governo ainda, assim, possui um forte papel fornecendo suporte - político ou financeiro - para a realização desses projetos inovadores. Para Etzkowitz e Mello (2004), a atuação 
do governo tem foco na coordenação e no estímulo aos processos de geração e disseminação do conhecimento, no aporte de recursos e na mobilização da sociedade e dos agentes econômicos, por meio da criação e do suporte a programas, projetos e instituições promotoras do desenvolvimento de ambientes favoráveis à inovação, os quais poderão, no futuro, transformar-se em sistemas regionais ou nacionais de inovação.

Consequentemente, de acordo com os formuladores do modelo, "a metáfora da Hélice Tríplice é útil como uma moldura analítica para a compreensão dos processos de inovação e a proposição e implementação de políticas públicas, especialmente de ciência, tecnologia e inovação que visem ampliar e suportar a interação entre os atores das diferentes hélices" (ETZKOVITZ; LEYDESDORFF, 2000, p. 112). Essa simbiose entre os atores constituintes das três hélices do sistema proposto, bem como as redes trilaterais e as organizações híbridas (as quais agregam as características dos três atores do modelo) podem ser ilustradas conforme a figura a seguir:

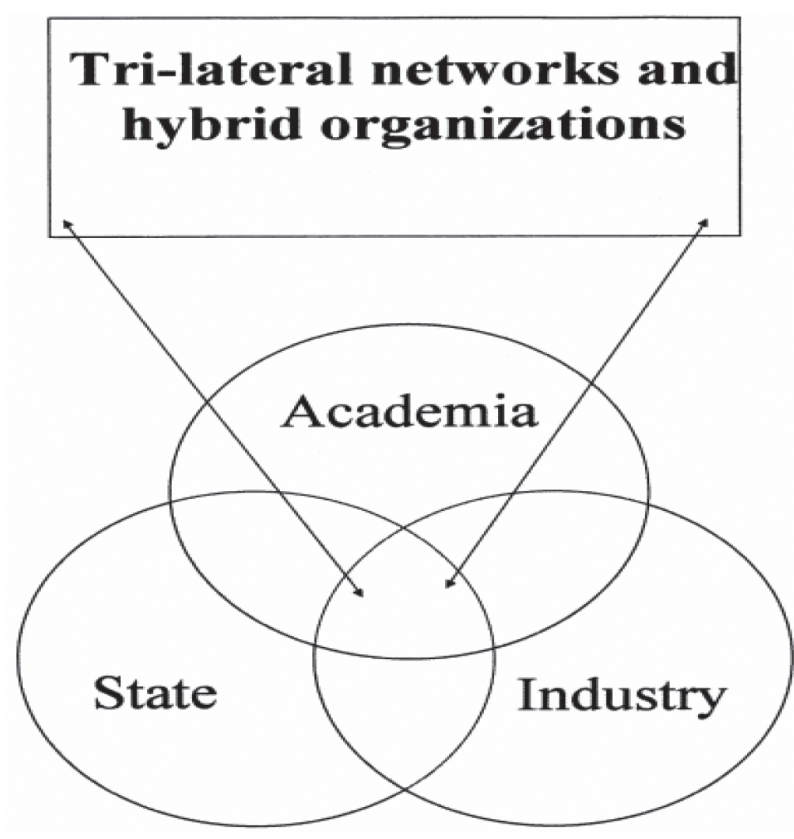

Figura 1 - O Sistema Tríplice Hélice

Fonte: Etzkowitz e Leydesdorff (2000)

\section{METODOLOGIA}

O presente artigo é um estudo de caso e pode ser classificado como exploratório e descritivo. O método utilizado foi o qualitativo, com o uso de entrevistas semiestruturadas e análise documental.

A escolha do método de estudo de caso parece ser a mais adequada para o desenvolvimento deste trabalho. Já que, conforme Yin (2001, p. 54), “o estudo de caso é uma investigação empírica de um fenômeno contemporâneo em um contexto da vida real, sendo que os limites entre o fenômeno e o contexto não estão claramente definidos". Além disso, o estudo de caso é um instrumento de investigação, uma modalidade de pesquisa que pode ser aplicada em diversas áreas do conhecimento (VENTURA, 2007). 
O objetivo com o estudo exploratório, por sua vez, foi pesquisar o papel das incubadoras no processo de desenvolvimento local e regional, bem como sua atuação como eixo de ligação entre os atores do Modelo da Tríplice Hélice. Como estudo descritivo, foram analisados artigos, dissertações, teses, livros e documentos eletrônicos sobre a incubadora, sua história e os personagens que mais influenciaram sua trajetória de transformações, bem como sobre as instituições e o papel que elas representaram e ainda representam para a situação estudada.

A coleta de dados de campo foi feita por meio de entrevistas semiestruturadas com os personagens que atuaram diretamente na gestão e coordenação da incubadora desde seu início até o presente. $\mathrm{O}$ estudo procurou abordar, assim, as seguintes questões:

- de que forma as ações da ITSM se assemelham com as ações propostas no modelo de Henry Etzkowitz e Loet Leydesdorff?

- por que é possível dizer que a ITSM é um caso de sucesso do modelo Tríplice Hélice?

\section{DESENVOLVIMENTO E PRINCIPAIS RESULTADOS EN- CONTRADOS}

As instituições de ensino e de pesquisa tecnológica têm como obrigação primeira acompanhar o processo de inovação e de mudança de paradigmas. A empresa inovadora, forte dependente de novas tecnologias e novos conhecimentos para o sucesso de seus negócios, de certa forma, também é dependente dos esforços despendidos pelo corpo de pesquisadores das instituições, para ver suas aspirações contempladas.

O processo de transferência de novos conhecimentos pode ser um eficiente instrumento para transformar as ideias e pesquisas geradas nas instituições, em processos produtivos ao alcance do empreendedor, de forma a possibilitar a sua inserção no mercado de trabalho e, consequentemente, a inclusão social.

Aqui se destaca o papel da Incubadora Tecnológica de Santa Maria (ITSM), que está localizada em prédio próprio à entrada do Campus da Universidade Federal de Santa Maria (UFSM). A ITSM foi instituída por meio da Portaria n.. 025/99-CT, de 15 de março de 1999, como projeto de extensão do Centro de Tecnologia (CT), a fim de apoiar novos empreendedores e transformar ideias em negócios, buscando contribuir para a formação de uma mentalidade empresarial inovadora na região central do Rio Grande do Sul. Os primeiros empreendimentos selecionados ocuparam seus módulos no dia 10 de agosto de 1999, quando a Incubadora passou a operar oficialmente.

As áreas preferenciais de atuação são eletrônica, design, agronegócio e informática. Porém, todos os projetos que tenham como principal insumo o conhecimento, que sejam inovadores, que não prejudiquem o meio ambiente e que demonstrem, por meio de seu Plano de Negócios, viabilidade técnica e econômica, são recebidos e avaliados pelo Conselho de Administração da Incubadora.

O Modelo de Incubação da ITSM, de acordo com o atual gestor da incubadora, Frank Csado, "contempla o apoio de projetos empresariais de base científico e/ou tecnológica em três momentos distintos e complementares: a fase da ideia e a sua concretização num plano de negócios e a apresentação deste plano, desencadeando na criação da empresa, a concepção tecnológica do produto e/ou serviço na incubação e a fase da graduação ou consolidação do empreendimento no mercado". Na figura a seguir, estão esquematizadas as fases constituintes do processo de incubação e respectivas durações. 


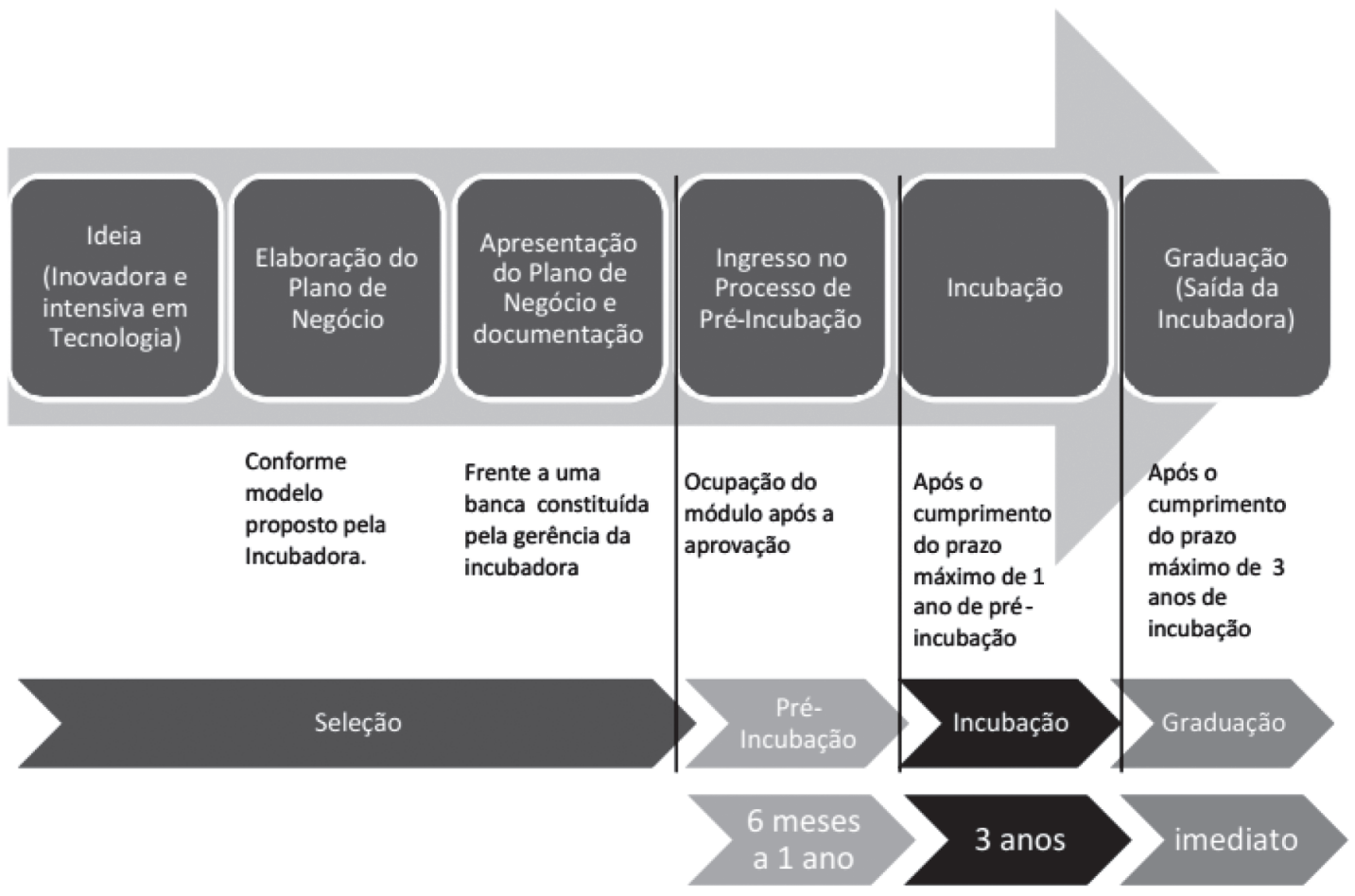

Figura 2 - Modelo de Incubação da ITSM

Fonte: Manual da ITSM (2012)

Assim sendo, a ITSM atua com duas formas de residência, a pré-incubação e a incubação. A pré-incubação surgiu logo no seu primeiro ano de existência devido ao fato de não haver ainda, naquela época, empresas formalizadas para entrar no sistema de incubação. O que havia, naquele momento, eram projetos, os quais, desde que amparados e orientados, eram capazes de se transformar em um negócio no futuro. Dessa maneira, a modalidade de pré-incubação foi a primeira forma de residência na ITSM.

Segundo Labiak (2012), o processo de pré-incubação corresponde a um spin-off de uma pesquisa de laboratório, em que se tem a percepção da oportunidade que irá se constituir em uma ideia inovadora. Nesse ambiente propício, é feito o acompanhamento do projeto que está sendo colocado em prática por meio do desenvolvimento do planejamento empresarial da futura empresa, com base em estudos de viabilidade tanto técnica quanto econômica, bem como no plano de negócios.

De acordo com o Manual da ITSM (2012), nessa fase de pré-incubação, a ênfase é dada ao plano de negócios, à pesquisa de mercado e à preparação dos empreendedores sobre gestão de negócios, com o objetivo de preparar os empreendimentos para a permanência na incubadora. Essa fase se caracteriza, também, pelos testes de protótipos dos produtos, serviços ou processos inovadores; pelo desenvolvimento de redes sociais - relações com potenciais clientes, fornecedores; e pelo estabelecimento da equipe de gestão, entre outros fatores fundamentais para o estabelecimento do negócio.

Ao final do período de um ano, a ideia da empresa, ou seja, o projeto colocado em prática, é reavaliado (conforme critérios próprios da gerência da incubadora) para observar as condições de permanência na incubadora; então, torna-se obrigatório que a empresa seja formalizada pelos gestores do projeto a fim de que os produtos/serviços possam ser comercializados durante o período de incubação. Nessa fase, de acordo com o atual gerente da ITSM, "o projeto que passou por uma avaliação positiva pela gerência da incubadora, deverá criar efetivamente 
a empresa, passando para uma fase de crescimento do produto, serviço ou processo inovador, através do crescimento da comercialização do mesmo e consequentemente dos rendimentos".

Conforme já citado, a fase de incubação tem duração de três anos (somados ao ano de pré -incubação, tem-se quatro anos de residência na ITSM) e caracteriza-se por ser um processo dinâmico, em que a incubadora presta auxílio para o crescimento da empresa no seu período inicial, fornecendo amparo com pessoal especializado nas áreas de gestão, acesso à financiamento e apoio técnico.

Aos residentes da ITSM, seja em fase de pré-incubação ou incubação, é oferecido um ambiente compartilhado de secretaria, cozinha, banheiros, auditório e área de convivência com churrasqueira. Além da locação de espaço físico com internet, energia elétrica e segurança $24 \mathrm{~h}$ para instalação da empresa, são fornecidas consultorias e treinamentos para os gestores e seus colaboradores.

Terminado o período de quatro anos de residência (um ano destinado à pré-incubação e três anos destinados à incubação), a empresa passará por uma avaliação final, o que permitirá um parecer sobre se o negócio tem condições de graduar-se ou se necessita de mais um ano para consolidar-se. Entende-se, de acordo com o Manual da ITSM (2012), que as condições para graduação são: tecnologia desenvolvida, estabilizada e consolidada no mercado, tendo a empresa, por meio de sua experiência obtida nos processos anteriores, condições de se estabelecer no mercado sem a ajuda e o acompanhamento da incubadora.

De acordo com dados obtidos junto à gerência da incubadora, em relação aos empreendimentos pré-incubados, incubados e graduados, o projeto apresenta os seguintes resultados até o momento:

- 18 empresas atualmente residentes, sendo sete em fase de incubação e 11 em pré -incubação, com cerca de 100 empreendedores, 50 colaboradores envolvidos e expectativa de receita de aproximadamente $\mathrm{R} \$ 4$ milhões para o ano de 2013;

- 25 empresas graduadas e inseridas no mercado até o momento;

- 68 projetos spin-off ou start-up prospectados e com Planos de Negócio apresentados para ingresso na ITSM;

- 720 acadêmicos de instituições de ensino visitaram a ITSM durante o ano de 2012;

- 110 pessoas participaram dos cursos de gestão promovidos pelo projeto em 2012;

- 25 palestras sobre empreendedorismo foram ministradas em 2012.

Entretanto, para se chegar a esses dados, que demonstram a solidez do projeto, foi necessário quebrar algumas barreiras e paradigmas que se impuseram no caminho. Uma das principais dificuldades enfrentadas pela incubadora em seus anos iniciais foi o fato de que, ao criar um ambiente empresarial dentro de uma instituição de ensino pública, trazia à tona o receio que permeava os pensamentos dos brasileiros durante os anos 1990: a privatização. Ressalta-se, assim, que o projeto foi criado e colocado em funcionamento durante o segundo mandato do ex -presidente Fernando Henrique Cardoso, em que a atuação do Estado se viu diminuída e muitas empresas estatais foram privatizadas, como a Rede Ferroviária Federal (por meio de concessão), a Vale do Rio Doce, a CPFL Energia e o Sistema Telebrás (que envolvia 27 empresas de telefonia fixa e 26 de telefonia celular). Desse modo, havia o forte receio de que a onda de privatizações pudesse atingir as universidades federais, circunstância corroborada pela ideia da criação de empresas privadas dentro de universidades públicas, algo não usual na época e que contribuía para a desconfiança dos que viviam o receio das privatizações.

Por isso que, conforme mencionado anteriormente, a ITSM foi criada na forma de projeto de extensão e assim permanece até hoje. Segundo a professora Nilza Zampieri, idealizadora e coordenadora da ação, "um projeto de extensão foi a maneira ideal encontrada para viabilizar 
a proposta de criação da incubadora, já que, a extensão universitária é uma ação da universidade junto à comunidade, disponibilizando ao público externo o conhecimento adquirido com o ensino e a pesquisa desenvolvidos".

Assim, o fato de ser um projeto de extensão universitária contribuiu para a confiança de que a proposta de estimular a criação de empresas dentro da universidade ia ao encontro do desenvolvimento local, pois o contato imediato da comunidade interna de uma determinada Instituição de Ensino Superior (IES) com a sua comunidade externa, em geral a sociedade a que ela está subordinada, é fundamental. A ideia de extensão está associada à crença de que o conhecimento gerado pelas instituições de pesquisa deve necessariamente possuir intenções de transformar a realidade social, intervindo em suas deficiências e não se limitando apenas à formação dos alunos regulares daquela instituição.

Por conseguinte, para agregar credibilidade ao projeto, foi necessário estabelecer alianças externas à UFSM. O primeiro contato com uma entidade empresarial foi feito por intermédio da Câmara de Comércio e Indústria de Santa Maria (CACISM), entidade com 114 anos de existência e que tem foco na expansão empresarial, buscando desenvolvimento econômico, social e cultural do município por meio da realização de cursos, workshops, parcerias e feiras - a maior delas, a Multifeira de Santa Maria (FEISMA) realizada em uma área de 16,5 mil metros quadrados, nos quais é apresentado um grande panorama das potencialidades da cidade e da região, possibilitando visibilidade a 394 expositores da indústria, do comércio e de serviços, distribuídos em 497 estandes, contou com um público visitante de 139 mil pessoas em sua última edição, de acordo com dados da organização do evento. Assim, a primeira ação conjunta entre a incubadora e a CACISM foi a inserção das empresas incubadas na FEISMA, de modo que estas pudessem participar da feira mostrando os produtos e serviços em um espaço destinado às inovações tecnológicas desenvolvidas na cidade.

Dessa maneira, além da chancela de uma entidade consolidada na cidade, as empresas ainda podem desfrutar da possibilidade de expor, anualmente e sem nenhum custo para o empreendimento, os produtos que desenvolvem e, com isso, facilitar a comercialização dos produtos e serviços junto ao público consumidor em geral.

Outra importante ligação feita pela incubadora foi realizada com a prefeitura municipal de Santa Maria desde o início do funcionamento da ITSM. A prefeitura municipal de Santa Maria demonstrou, por meio de cartas de apoio, sua aprovação quanto ao projeto, bem como disponibilizou um espaço físico para o início das atividades. Entretanto, como também havia sido pleiteado um espaço dentro da própria UFSM, o projeto acabou por instalar-se nesta instituição.

Outro marco importante para o desenvolvimento do sistema de inovação do município consiste no projeto de lei da primeira Lei de Inovação Municipal do país em 2010 (no bojo da Lei de Inovação de 2004), a qual surge com o intuito de complementar a lei federal e atender às especificidades e necessidades de Santa Maria, através da regulamentação das parcerias estratégicas entre as universidades, os institutos tecnológicos e as empresas. Assim, a então Lei Municipal n. 5306 estabeleceu medidas de incentivo à inovação e à pesquisa científica e tecnológica na cidade de Santa Maria, visando à capacitação em ciência, tecnologia e inovação e ao desenvolvimento econômico e social sustentável do município.

Segundo Gubiani (2011), a Lei de Inovação estimula a participação de Instituições de Ciência e Tecnologia no processo de inovação e autoriza a incubação de empresas no espaço público e o compartilhamento de infraestrutura de equipamentos e dos recursos humanos públicos e privados. Assim, essa Lei se torna um marco para o apoio ao desenvolvimento tecnológico e um importante alicerce tanto para incubadoras como para parques e polos tecnológicos. 
Importante órgão criado a partir da ITSM e da Lei de Inovação é o Polo de Inovações Tecnológicas e Sociais da UFSM, o qual, segundo seu coordenador, José Brutti, "se destina a promover atividades de desenvolvimento empresarial baseados em pesquisa e sustentabilidade social, ambiental, cultural e econômica, caracterizadas pelos preceitos da inovação tecnológica e social de empreendimentos que sejam decorrentes de geração institucional, cooperação privada, governamental e não governamental com a UFSM, ou que tenham participado do processo de incubação na UFSM".

Ainda de acordo com o coordenador, "o Polo/UFSM é uma iniciativa pioneira que nasce da necessidade de prover a universidade de um espaço próprio para abrigar empreendimentos que necessitem de apoio tecnológico e laboratorial para desenvolver seus negócios". Assim, pode-se constatar a consolidação de um ambiente propício para o desenvolvimento tecnológico no espaço universitário, em que os negócios começam a se desenvolver na incubadora e, ao graduarem-se, podem seguir dentro do âmbito acadêmico, instalando-se no Polo Tecnológico.

Da mesma forma, a fim de ampliar a contribuição para o desenvolvimento econômico e social do município e da região, por meio do incentivo à disseminação da cultura empreendedora no âmbito regional, transformando ideias em negócios, com base na pré-incubação e na incubação de projetos originados na comunidade e principalmente nas universidades e na atração de empresas para o parque, criando um ambiente apropriado para a transferência de tecnologia ao setor produtivo e capacitando técnica e gerencialmente os empreendedores, foi criado o Santa Maria Tecnoparque (SM Tecnoparque).

O SM Tecnoparque foi projetado com base na interação entre o município, a universidade e a iniciativa privada e, importante salientar, presidido pela coordenadora da ITSM. Esse parque foi fundado por sete instituições da cidade - incluindo universidades, prefeitura e CACISM - e tem por missão catalisadora o desenvolvimento regional, por meio da promoção da interface entre tecnologia e mercado, gerando oportunidades para empreendimentos existentes e para novos empreendimentos, intensivos em tecnologia e de alto valor agregado. O SM Tecnoparque começou suas obras em 2010 e foi inaugurado no dia 13 de dezembro de 2013, estando em funcionamento desde sua inauguração.

A ITSM também serviu de estímulo para outra importante iniciativa, o Comitê de Empreendedorismo e Inovação de Santa Maria, o qual, assim como o SM Tecnoparque, é presidido pela professora Nilza Zampieri, coordenadora da incubadora e incentivadora do empreendedorismo na região. O Comitê de Empreendedorismo é composto por órgãos públicos, entidades empresariais e instituições de ensino da cidade e procura promover o desenvolvimento sustentável de Santa Maria, fortalecendo a cultura empreendedora e a inovação, aproveitando as potencialidades existentes e criando novas oportunidades de empreendimentos. Esses objetivos são alcançados por meio de algumas ações, das quais se destacam:

- disseminação da cultura empreendedora por meio do treinamento e da capacitação dos professores do Ensino Fundamental, Médio e Superior;

- integração com o poder público para estimular a desburocratização, apoiar a criação e melhoria da legislação voltada ao empreendedorismo e à inovação, facilitar o acesso à informação, atrair investimentos e valorizar as empresas locais;

- implantação do Parque Tecnológico em Santa Maria, a fim de apoiar a disseminação da inovação tecnológica e criar um Conselho de Inovação Tecnológica em Santa Maria.

Dessa forma, percebe-se que a ITSM não é só uma fornecedora de empresas de sucesso, mas também uma promotora ativa do empreendedorismo e do desenvolvimento sustentável. Tais características se tornam mais relevantes quando se verifica o reconhecimento da população em relação ao trabalho realizado, pois, conforme o atual gestor da ITSM, profissionais de outras insti- 
tuições de ensino visitam a Incubadora regularmente a fim de obter informações para a criação de suas incubadoras de empresas e também para entender como foi feita a interação entre as diferentes esferas (universidade-governo-empresas), as quais são fundamentais para que uma incubadora atinja seu objetivo de contribuir para o desenvolvimento local e regional onde está inserida.

\section{DISCUSSÃO E CONCLUSÕES}

Observamos que o movimento de surgimento do Sistema Tríplice Hélice se funde historicamente com o movimento para a criação da ITSM, já que, no mesmo espaço histórico, porém em diferentes ambientes físicos, econômicos e principalmente culturais, duas situações semeIhantes desenvolveram-se.

Assim, é importante destacar que o ambiente tecnológico e inovador que se instituiu na ITSM só foi possível devido à interação entre governo-universidade-empresas. Ressalta-se que esses atores, até os dias de hoje, estão em grande sintonia, indicando a tendência de permanência dessa interação. A expectativa é, assim, que as universidades formem agentes multiplicadores das ações de inovação e mudança, que os governos contribuam com a criação, o aperfeiçoamento e a consolidação de políticas públicas e com mecanismos de fomento a essas ações e que as empresas integrem, baseadas na responsabilidade social, os projetos de desenvolvimento como parceiras dos dois outros atores (SILVA, TERRA e VOTRE, 2006).

Na imagem a seguir (Figura 3), ilustra-se a ITSM como uma organização híbrida dentro do Sistema Tríplice Hélice, que, conforme Etzkowitz e Leydesdorff (2000), seria um dos tipos de organização que está emergindo das interfaces principais propostas no Sistema.

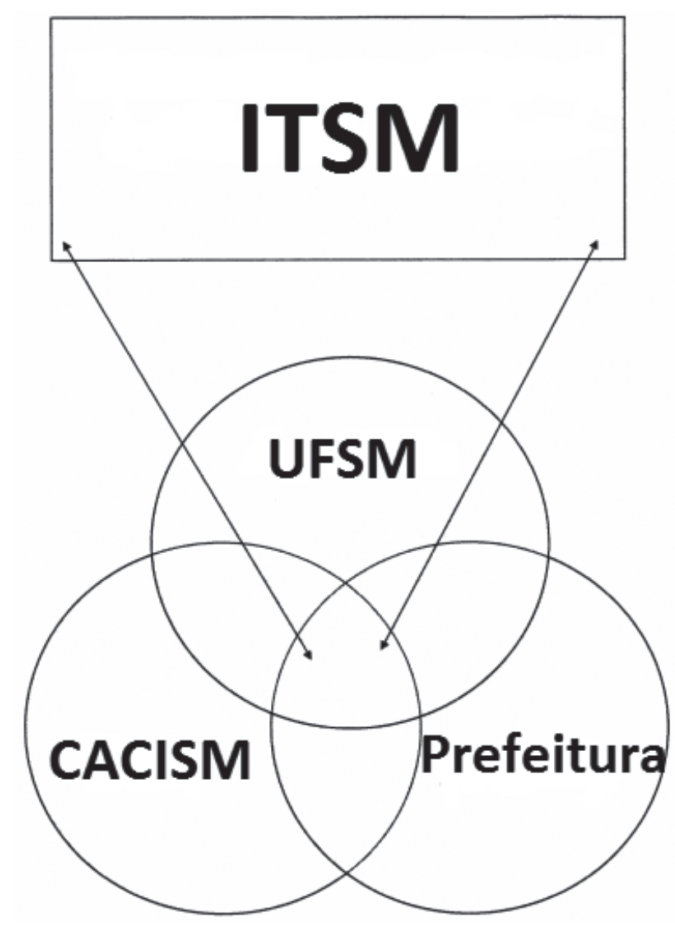

Figura 3- Modelo Hélice Tripla de Santa Maria 
No modelo, a esfera que representa o governo inclui a Prefeitura Municipal de Santa Maria. Ao lado, a esfera da academia é representada pela UFSM, a esfera das empresas é simbolizada pela CACISM. Finalmente, a ITSM é a organização híbrida que surge, reunindo as três esferas e suas características.

Assim, é possível visualizar a interação entre todos os atores envolvidos nas ações referentes ao desenvolvimento das inovações tecnológicas no município. Nesse contexto, as universidades compartilham ambientes e competências profissionais para criar o conhecimento, o qual funciona como base para as empresas criarem novos negócios, serviços, empresas e empregos. O governo, por seu turno, fomenta a inovação, englobando a universidade e a indústria, dirigindo as ações entre elas e propiciando o surgimento de negócios intensivos em alta tecnologia.

De acordo com os relatos feitos pelos gestores e pela coordenadora do projeto, foi possível notar as dificuldades de criar no interior do Estado, em uma cidade com pouca ou quase nenhuma tradição industrial, uma incubadora de empresas de base tecnológica, que primasse pelo desenvolvimento de altas tecnologias na cidade. Outro empecilho que se pode verificar é a escassa mão de obra dedicada para a gestão da ITSM. Durante os primeiros onze anos de atividade, o projeto contou apenas com a professora coordenadora e com um servidor técnico administrativo da UFSM para conduzirem os trabalhos da incubadora e auxiliar as empresas nascentes, as quais aumentaram em número ano a ano, desde 1999 (ano de inauguração do projeto) até o momento.

Inicialmente, o espaço físico da incubadora era de dez módulos, banheiros, auditório, sala de administração e cozinha. Com a crescente procura, a sala de auditório foi extinta para dar lugar a um espaço compartilhado para duas empresas. Em 2009, ocorreu a primeira ampliação da ITSM, quando foram construídos mais dois banheiros e dois módulos para incubação e um auditório; entretanto, a carência por espaço fez com que o auditório se transformasse em mais um módulo para abrigar outra empresa. Posteriormente, em 2012, a Incubadora recebeu o acréscimo de um auditório e uma área de convivência com churrasqueira com espaço para eventos, onde são realizadas palestras, encontros e festividades entre os empreendedores.

Assim, nota-se a expansão constante do projeto, que começou em uma área de $400 \mathrm{~m}^{2}$ e hoje, após as ampliações, possui $700 \mathrm{~m}^{2}$ de área construída. Com o passar dos anos e a notoriedade do movimento de incubadoras no Brasil, a ITSM conseguiu recursos junto ao Ministério da Ciência e Tecnologia (MCT) e à Secretaria de Ciência, Inovação e Desenvolvimento Tecnológico (SCTI/RS) para suas obras de ampliação, bem como para a realização de cursos de gestão para os empreendedores das empresas residentes. Hoje, a incubadora possui fila de espera para novos negócios, e, no processo seletivo de 2013, inscreveram-se sete planos de negócio, dos quais, quatro foram selecionadas para o sistema de pré-incubação e já se encontram instalados na ITSM.

\section{RECOMENDAÇÕES}

Este estudo careceu de ter realizado entrevistas com os demais atores envolvidos no Sistema Tríplice Hélice proposto, visto que foram feitas entrevistas somente com os gestores e a coordenadora da ITSM e não com os demais envolvidos nos outros órgãos citados, especialmente os outros dois atores do sistema, CACISM e Prefeitura Municipal de Santa Maria. Assim, pretende-se, no futuro, ampliar a pesquisa de forma a tornar o trabalho mais completo por meio de análise documental dos demais integrantes do sistema. Também se faz necessária entrevista com os prefeitos e demais agentes municipais diretamente envolvidos com o desenvolvimento da Incubadora, desde seu início até os dias atuais, bem como com os representantes da Câmara de Comércio e Indústria e também com as empresas atualmente residentes e as já graduadas, todos importantes elementos que participaram da história da ITSM durante os 15 anos de atividade do projeto até o momento. 


\section{REFERÊNCIAS}

ARANTES, A. P.; SERPA, C. V. O modelo da tríplice hélice como fator de desenvolvimento de Santa Rita do Sapucaí. XXII Seminário Nacional de Parques Tecnológicos e Incubadoras de Empresas.ANPROTEC, 2012.

ASSOCIAÇÃO NACIONAL DE ENTIDADES PROMOTORAS DE EMPREENDIMENTOS INOVADORES. Estudo, análise e proposições sobre as incubadoras de empresas no Brasil - relatório técnico. Ministério da Ciência e Tecnologia - Brasília: ANPROTEC, 2012. Disponível em: <http://www.anprotec.org. br/ArquivosDin/Estudo_de_Incubadoras_ Resumo_web_22-06_FINAL_pdf_59.pdf >. Acesso em 20 de julho de 2012.

BAÊTA, A.M.C. O desafio da criação: uma análise das incubadoras de empresas de base tecnológica. Petrópolis, RJ: Vozes, 1999.

CÂMARA DE COMÉRCIO E INDÚSTRIA DE SANTA MARIA. http://www.cacism.com.br Acesso em: 22 de julho de 2013.

CHAVES, D.C.R.AUniversidade Empreendedora do séc. XXI: O Papel Estratégico da Propriedade Industrial. Dissertação de Mestrado. Faculdade de Economia da Universidade de Coimbra, 2009.

DIAS, C.; CARVALHO, L. F. Panorama mundial de incubadoras. In: Modelo de gestão para incubadoras de empresas, 2002

ETZKOWITZ, H.; LEYDESDORFF, L. The dynamics of innovation: from National Systems and "Mode 2" to a Triple Helix of universityindustry-government relations. Research Policy v. 29, 2000.

ETZKOWITZ, H.; MELLO J.M.C.The Rise of a Triple Helix Culture - Innovation in Brazilian Economic and Social Development, International Journal of Technology Management and Sustainable Development, 2 (3) 159- 171, 2004.
ETZKOWITZ, $\mathrm{H}$., Mello $\mathrm{J} \mathrm{M}$ and Almeida, $\mathrm{M}$. Towards "meta-innovation" in Brazil: The evolution of the incubator and the emergence of a triple helix. ResearchPolicy, 34 (4), 2005.

FERRAZ, J.C. et al. Made in Brazil: desafios competitivos para a indústria. Rio de Janeiro: Campus, 1995.

GUBIANI, J. S. Modelo para Diagnosticar a Influência do Capital Intelectual no Potencial de Inovação nas Universidades. Tese de Doutorado. Programa de Pós-Graduação em Engenharia e Gestão do Conhecimento da UFSC, 2011.

iDICS -Toolkit. Incubatormodels.2012. Disponível em:<http://www.idisc.net/en/ ToolkitPrint.aspx>. Acesso em: 10 março de 2012.

INCUBADORA TECNOLÓGICA DE SANTA MARIA. Manual da ITSM. Disponível em: http://ufsm. br/itsm. Acesso em 20 junho de 2012.

LABIAK, S. Método de Análise dos Fluxos de Conhecimento em Sistemas Regionais de Inovação. Programa de Pós-Graduação em Engenharia e Gestão do Conhecimento,2012.

MELLO, J. M. C., PIMENTA N. L., LIMA M. S., A Hélice Tríplice e Desenvolvimento Regional: criação e disseminação de conhecimentos em Fármacos e Cosméticos e Piscicultura no Estado do Amazonas. XI Seminário LatinoIberoamericano de Gestión Tecnológica,2005

MINISTÉRIO DA CIÊNCIA E TECNOLOGIA. Apoio ao desenvolvimento tecnológico de empresas. PNI - Incubadoras de Empresas e Parques Tecnológico. 2012. Disponível em: <http://www.mct.gov.br/index.php/content/ view/5228.html>. Acesso: 10 março de 2012.

PALETTA, F.C. Tecnologia da informação, Inovação e empreendedorismo: fatorescríticos de sucesso no uso de ferramentas de gestão em empresas Incubadas de base tecnológica. 2008. 143 p. Tese de Doutorado (Instituto de Pesquisas Energéticas e Nucleares). Autarquia 
Associada à Universidade de São Paulo, São Paulo,2008.

PORTER, M. CompetitiveStrategy: Techniques for Analyzing Industries andCompetitors. Free Press,2002.

SEBRAE. MPEs de Base Tecnológica: conceituação, formas de financiamento e análise de casos brasileiros. 2001. Disponível em: <http://antigo.sp.sebrae. com.br/principal/conhecendo\%20a\%20mpe/ estudos\%20setoriais\%20e\%20regionais/ documentos_estudos_setoriais/embatec. pdf>. Acesso em: março de 2012.

SILVA, C. A. F., TERRA B. R. C., VOTRE S. J. O Modelo da Hélice Tríplice e o Papel da Educação Física, do Esporte e do Lazer no Desenvolvimento Local. Rev. Bras. Cienc. Esporte, Campinas, v. 28, n. 1, p. 167-183, set. 2006.

TIDD, J.; BESSANT, J.; PAVIT, K. Gestão da Inovação. 3 ed. Artmed. São Paulo, 2005.

VEDOVELLO C., PUGA F. P., FELIX M. Criação de Infra-Estruturas Tecnológicas: A Experiência Brasileira de Incubadoras de Empresas. Revista do BNDES, Rio de Janeiro, v. 8, n. 16, p. 183214, dez., 2001.

VEnTURA, M. M. O Estudo de Caso como Modalidade de Pesquisa. Rev SOCERJ, 2007

YIN, R. K. Estudo de Caso: planejamento e métodos. 2 ed. Porto Alegre: Bookman, 2001.

ZAMPIERI, N. L. V. Empreendedorismo de Base Tecnológica e Desenvolvimento Regional. Dissertação de mestrado, Programa de Pós-Graduação Engenharia de Produção, Universidade Federal de Santa Maria, 2010.

ZAMPIERI, N. L. V.; CASADO, F. L.; FLORES, G. T. F. O Papel da ITSM na Consolidação da Formação de Engenheiros Empreendedores. COBENGE, Blumenau, SC, 2011. 